\title{
Silver-Functionalized Bacterial Cellulose as Antibacterial Membrane for Wound-Healing Applications
}

\author{
Sudipto Pal, ${ }^{\dagger}{ }^{\dagger}$ Rossella Nisi, ${ }^{\dagger}$ Mariangela Stoppa, ${ }^{\dagger}$ and Antonio Licciulli ${ }^{\dagger}$ \\ ${ }^{\dagger}$ Department of Engineering for Innovation, University of Salento, via Monteroni, 73100 Lecce, Italy \\ ${ }^{\ddagger}$ Biofaber srl, Via Luigi di Savoia 19, 72023 Mesagne, BR, Italy
}

Supporting Information

ABSTRACT: Bacterial cellulose (BC) functionalized with silver nanoparticles (AgNPs) is evaluated as an antimicrobial membrane for wound-healing treatment. A facile green synthesis of silver nanoparticles inside the porous three-dimensional weblike BC network has been obtained by UV light irradiation. AgNPs were photochemically deposited onto the BC gel network as well as they were chemically bonded to the cellulose fiber surfaces. AgNPs with a narrow size distribution along with some aggregates in the $\mathrm{BC}$ network were evidenced from the morphological analyses. A highly crystalline nature of the $\mathrm{BC}$ membranes was observed in X-ray diffraction measurements, and the presence of metallic silver confirmed the photochemical reduction of $\mathrm{Ag}^{+} \rightarrow \mathrm{Ag}^{0}$ in $\mathrm{Ag} / \mathrm{BC}$ composites. Antibacterial activity of the hybrid composites, such as
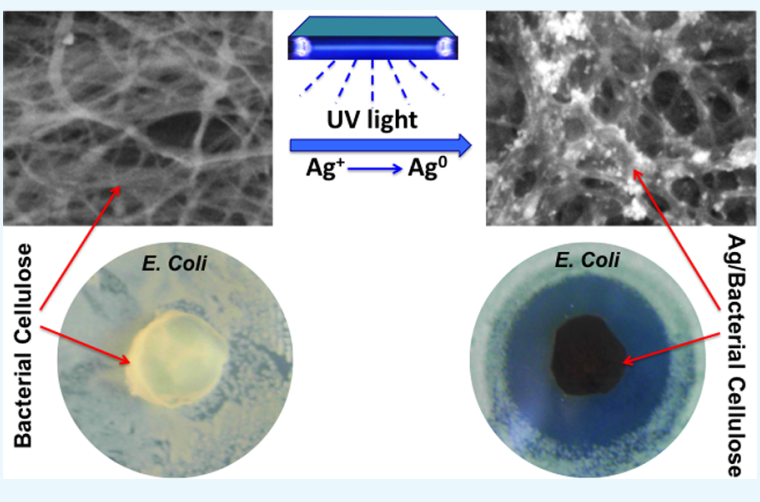
pellicles, performed against the Gram-negative bacteria (Escherichia coli) by disk diffusion and growth dynamics methods showed high bacteria-killing performance. No significant amount of silver release was observed from the $\mathrm{Ag} / \mathrm{BC}$ pellicles even after a long soaking time. As composite pellicles are preserved in a moist environment that also favors wound recovery, by combining all of these properties the material could be useful in wound-healing treatments.

\section{INTRODUCTION}

Bacteria-derived cellulose, commonly known as bacterial cellulose (BC), is produced by the fermentation of Gramnegative bacterium Acetobacter xylinum, which can produce high aspect ratio nanofibers, with three-dimensional (3D) porous networks. $^{1-5} \mathrm{BC}$ does not require a complicated extraction process and harsh chemical treatment while retaining the highest purity. ${ }^{4,6}$ Because of its unique $3 \mathrm{D}$ weblike nanofibrous network structure, it shows excellent mechanical properties and moldability, particularly in the wet form, which make it suitable to be produced in a desired shape. Because of its hydrophilic nature ( $99 \%$ of the constituents is water), flexibility, nontoxicity, good biocompatibility, and wide availability it has been extensively used in diverse fields from food and paper industry $^{7,8}$ to biomedical applications, such as skin therapy, drug delivery, regenerative medicine, artificial blood vessel, scaffold for tissue engineering, and wound care products. ${ }^{5,6,9-11}$ Another advantage of $\mathrm{BC}$ is the presence of a large amount of surface hydroxyl groups that makes it suitable for functionalization with various nanomaterials, exploring potential applications in various fields. BC is considered as a natural wound dressing material thanks to its high porosity with a nanofibrous network and higher water-retention capability, but BC itself does not show any antimicrobial activity. Therefore, to make it applicable in wound healing and to avoid secondary infection, it is advisable to functionalize $\mathrm{BC}$ with some antimicrobial agent.
Silver, either as nanoparticles $\left(\mathrm{Ag}^{0}\right)$, oxides (mainly $\mathrm{Ag}_{2} \mathrm{O}$ ), or in ionic forms $\left(\mathrm{Ag}^{+}\right)$shows excellent antibacterial activity. ${ }^{12-15}$ Since a long time it has been used as a broadspectrum antimicrobial agent against bacteria, fungi, and viruses. Nowadays, nanosilver is being used in many medical devices, including surgical ones as well as a disinfectant against hospital wastewater, due to its strong antibacterial activities. $^{16-19}$ One of the advantageous properties of silver over that of other microbial agents is its higher toxicity to microorganisms while exhibiting lower toxicity to mammalian cells. $^{20}$ Although there are some arguments on the toxicity of the released silver ions against microorganisms, ${ }^{21,22}$ most of the studies suggest its safe use with a maximum permitted dosage. ${ }^{22-26}$ However, in the case of a typical application like wound healing, silver has to be retained inside a solid support to properly apply over the affected area. Compared with common wound-treating materials such as cotton gauges, BC having specific characteristics of high porosity and water permeability is more favorable. For this reason, there is an increasing interest toward producing $\mathrm{Ag} / \mathrm{BC}$ hybrid materials for antimicrobial treatments. ${ }^{27-30}$ As BC contains a significant amount of surface hydroxyl groups, $\mathrm{Ag}^{+}$ions could be easily

Received: April 12, 2017

Accepted: June 26, 2017

Published: July 14, 2017 
attached to the $\mathrm{BC}$ nanofibrils by chemical bonding, which could act as the seeds for the Ag reduction process. There are several reported methods to prepare $\mathrm{Ag} / \mathrm{BC}$ nanocomposites, but most of them suffer from a prolonged synthesis process as well as need harmful chemicals that in turn become the source of impurities in the hybrid material itself. Photochemical reduction under UV radiation is one of the most environmentfriendly and fast reduction procedure to produce $\mathrm{Ag}$ nanoparticles in the cellulosic matrix that has not been explored much yet. ${ }^{31,32}$ In this article, we report the fabrication of silver nanoparticles deposited on the nanofibrillated $\mathrm{BC}(\mathrm{Ag} / \mathrm{BC})$ by photochemical reduction process using $\mathrm{UV}$ radiation. $\mathrm{BC}$ as well as $\mathrm{Ag} / \mathrm{BC}$ hybrid composite formation were fully characterized by X-ray diffraction (XRD), Fourier transform infrared spectra (FTIR), and field-emission scanning electron microscope (FESEM) analyses, and their antibacterial activity was investigated by the disk diffusion method and growth curve method using a model Gram-negative bacteria.

\section{RESULTS AND DISCUSSION}

$\mathrm{Ag} / \mathrm{BC}$ nanocomposite formation from Ag-impregnated pure $\mathrm{BC}$ under UV light irradiation is illustrated in Scheme $1 . \mathrm{Ag}^{+}$

Scheme 1. Artwork of Silver Nanoparticles Formation on the Nanofibrillated Cellulose Matrix ${ }^{a}$
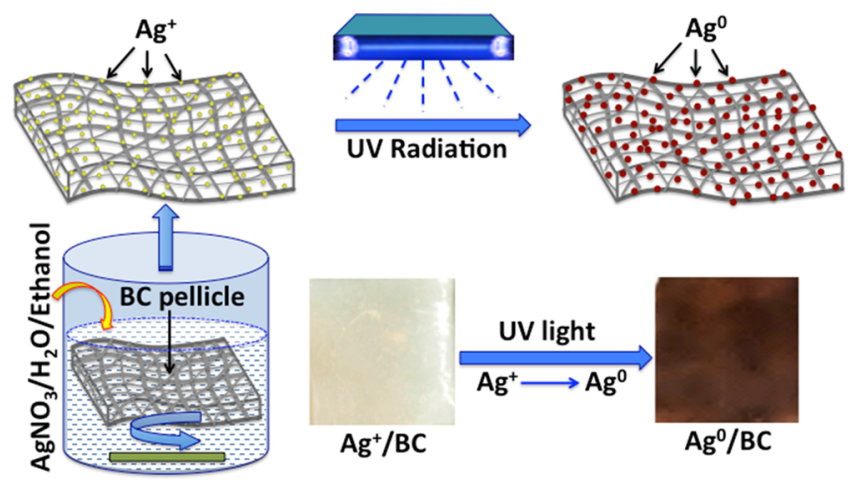

${ }^{a}$ Photographs of pellicles before and after UV irradiation are also presented.

ions were bonded to $\mathrm{BC}$ fibers after impregnation and became $\mathrm{Ag}$ nanoparticles after exposure to UV light, which is also evidenced by the color change of the composite from colorless to amber. Three $\mathrm{AgNO}_{3}$ concentrations $\left(10^{-2}, 10^{-3}\right.$, and $10^{-4}$ $\mathrm{M})$ were used as the impregnation medium. The amount of silver loading in $\mathrm{Ag} / \mathrm{BC}$ composites was determined by thermogravimetric analysis (TGA) and energy-dispersive $\mathrm{X}$ ray spectrometry (EDS) measurements and reported in Figure S1 and Table S1. Upon increasing the silver concentration, the color of $\mathrm{Ag} / \mathrm{BC}$ also changed from light gray to light amber to dark amber. Upon further increasing the silver concentration, $\mathrm{Ag} / \mathrm{BC}$ became blackish and any enhanced antibacterial activity was not observed. As Ag/BC pellicles impregnated with $10^{-2} \mathrm{M}$ $\mathrm{AgNO}_{3}$ showed the best antibacterial activity (discussed in the related section) and further Ag increment did not enhance the activity, all characterizations were performed with this $\mathrm{Ag}$ concentration, and the composite is named as $\mathrm{Ag} / \mathrm{BC}$ throughout the article unless mentioned otherwise.

Figure 1 shows the FTIR spectra of $\mathrm{BC}$ and silver nanoparticles-deposited $\mathrm{BC}$ composite $(\mathrm{Ag} / \mathrm{BC})$. The broad vibration band at $3200-3400 \mathrm{~cm}^{-1}$ region is assigned to the

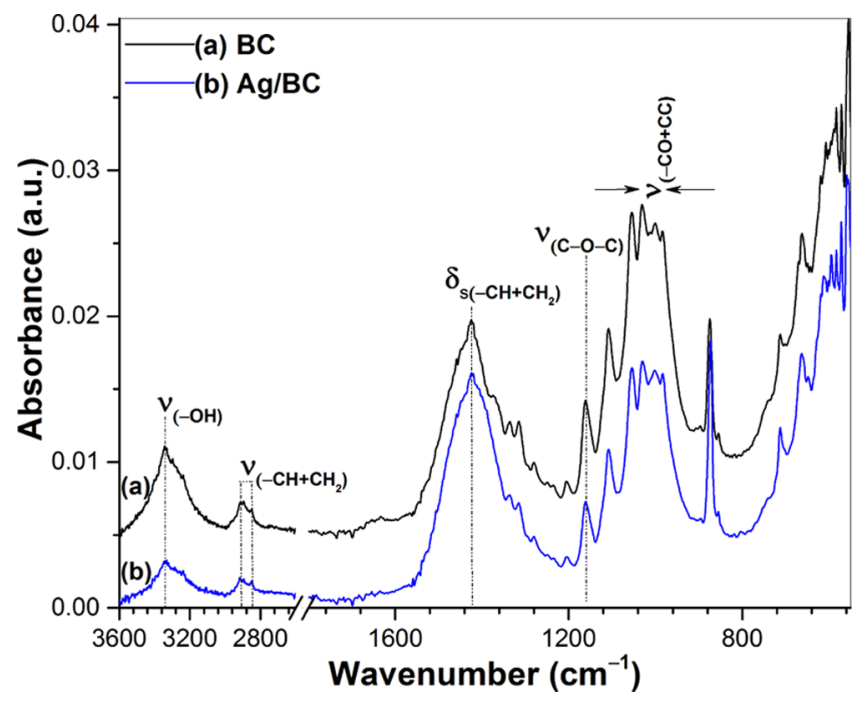

Figure 1. FTIR spectra of the (a) pure BC and (b) silver nanoparticles-deposited BC $(\mathrm{Ag} / \mathrm{BC})$ nanocomposite.

$\mathrm{OH}$ stretching vibration of the hydroxyl groups present in the BC network. ${ }^{2,33}$ Two relatively smaller bands at 2800-2900 $\mathrm{cm}^{-1}$ and a strong band at $1425 \mathrm{~cm}^{-1}$ are assigned to the stretching vibrations of $\mathrm{CH}$ and $\mathrm{CH}_{2}$, respectively. ${ }^{2,34}$ The absorption at $1158 \mathrm{~cm}^{-1}$ is coming from the $\mathrm{C}-\mathrm{O}-\mathrm{C}$ stretching vibration of the pure cellulose matrix. ${ }^{33}$ A group of absorption peaks at the wavenumber region of $1200-900 \mathrm{~cm}^{-1}$ arise due to the $\mathrm{C}-\mathrm{O}$ and $\mathrm{C}-\mathrm{C}$ stretching vibrations of the cellulose network. ${ }^{34}$ Relatively weaker peaks at lower wavenumbers are the characteristics of the fibril cellulose network. The absence of any vibrational band at $1387 \mathrm{~cm}^{-1}$ due to $\mathrm{NO}_{3}{ }^{-}$ in the $\mathrm{Ag} / \mathrm{BC}$ composite confirms the removal of nitrates from the composite material. ${ }^{35}$

The crystallinity of $\mathrm{BC}$ and $\mathrm{Ag} / \mathrm{BC}$ samples was evaluated from XRD analyses. Figure 2 shows the evolution of broad angle XRD patterns recorded on both samples. The appearance of strong diffraction peaks at $2 \theta$ of 14.4, 16.6, 22.6, 27.8, 29.3,

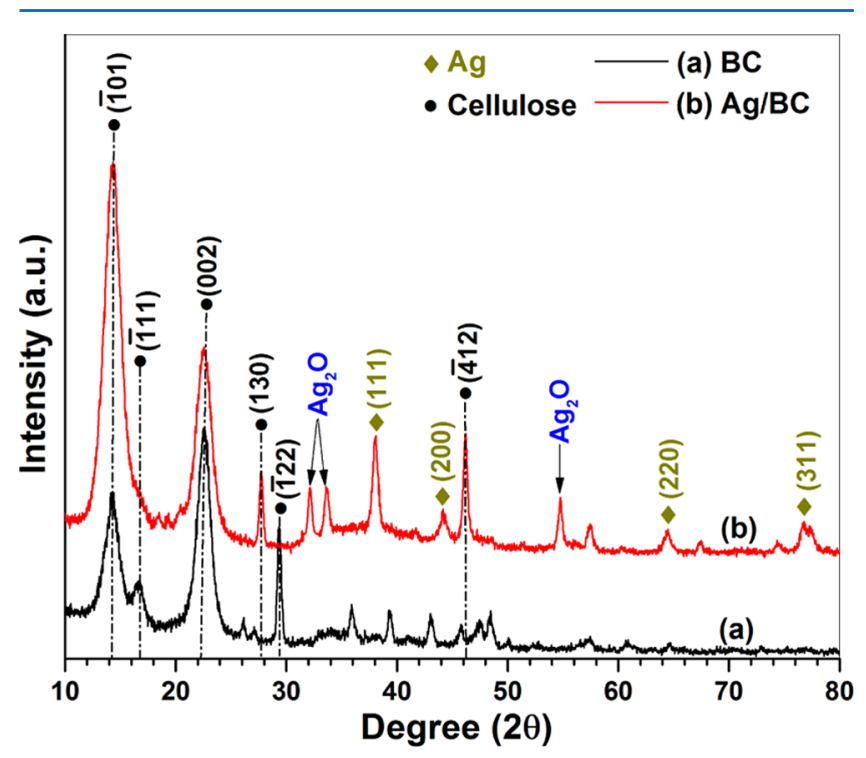

Figure 2. Wide-angle XRD pattern of (a) $\mathrm{BC}$ and (b) the $\mathrm{Ag} / \mathrm{BC}$ composite. The Bragg reflection planes of the respective crystallites are mentioned in the graph. 
and $46.2^{\circ}$ can be attributed to the Miller indices of the diffraction planes of (101), (111), (002), (130), (122), and (412), respectively, of crystalline cellulose (JCPDS \#030829). ${ }^{2,36}$ This set of diffraction planes corresponds to the highly crystalline native cellulose $\mathrm{I}$ that is composed of $\mathrm{I}_{\alpha}$ and $\mathrm{I}_{\beta}$ allomorphs. ${ }^{2}$ It is noteworthy that the $\mathrm{Ag} / \mathrm{BC}$ composite retains a similar crystallinity even after UV radiation exposure. The degree of crystallinity of the two samples was estimated according to the empirical equation of calculating the crystallinity index (CI) proposed by Segal et al. ${ }^{37}$

$$
\mathrm{CI}=100\left[\left(I_{002}-I_{\mathrm{am}}\right) / I_{002}\right]
$$

where $I_{002}$ is the principal diffraction peak at $2 \theta=22.6^{\circ}$ and $I_{\text {am }}$ is the intensity of the amorphous counterpart measured at $2 \theta=$ $18^{\circ}$. The estimated values are presented in Table 1 , wherein

Table 1. Physical Parameters Estimated from the XRD Analyses

$\begin{array}{lcccc}\text { samples } & \mathrm{CI}(\%)^{a} & \text { FWHM }^{b} & \left\langle D_{\text {av }}\right\rangle(\mathrm{nm})^{c} & d \text {-spacing }(\mathrm{nm}) \\ \mathrm{BC} & 86.8 & 1.539 & 5.26_{(002)} & 0.394 \\ \mathrm{Ag} / \mathrm{BC} & 81.4 & 1.658 & 4.79_{(002)} & 0.393 \\ \mathrm{Ag} & & 0.6426 & 12.36_{(111)} & 0.236 \\ \mathrm{Ag}_{2} \mathrm{O} & & 0.426 & 18.65_{(111)} & 0.277\end{array}$

${ }^{a}$ Crystallinity index. ${ }^{b}$ Full width half-maxima from the XRD peak. ${ }^{c}$ Average crystallite size using the Scherrer equation. $h k l$ parameters of the respective $2 \theta$ values used in the Scherrer equation are listed as subscript.

more or less similar crystallinity is observed. The average crystallite size of the nanocrystalline cellulose was estimated according to Scherrer's formula ${ }^{34}$

$$
\left\langle L_{002}\right\rangle=k \lambda / \beta \cos \theta
$$

where $L_{002}$ is the average crystallite size, $k$ is the shape factor (0.9), $\lambda$ is the X-ray wavelength, and $\theta$ is the Bragg angle corresponding to the intense (002) diffraction peak. The $\mathrm{Ag} /$ BC sample shows some well-defined additional diffraction peaks at $38.1,44.2,64.4$, and $76.7^{\circ}$ due to the (111), (200), (220), and (311) reflections of the face-centered cubic metallic silver (JCPDS \#76-1393), respectively, confirming the presence of silver nanoparticles in the $\mathrm{Ag} / \mathrm{BC}$ nanocomposite. The other peaks at 32.2 and $54.7^{\circ}$ due to (111) and (200) planes of cubic $\mathrm{Ag}_{2} \mathrm{O}$, respectively, and at $33.7^{\circ}$ due to the (100) plane of hexagonal $\mathrm{Ag}_{2} \mathrm{O}$ are also observed. ${ }^{38,39}$ The presence of $\mathrm{Ag}_{2} \mathrm{O}$ along with metallic silver is attributed to the $\mathrm{Ag}^{+} \rightarrow \mathrm{Ag}^{0}$ reduction process under UV radiation, as observed by the other researchers. $^{40}$

Morphological analyses are presented in Figure 3, which show FESEM images of the pure $\mathrm{BC}$ and $\mathrm{Ag} / \mathrm{BC}$ nanocomposites. Pure BC is composed of mainly 20-40 nm diameter cellulose nanofibers, forming a 3D weblike porous structure. The nanometer-sized fibers are distributed and interconnected in such a way so as to form a finely woven porous structure. This special characteristic helps the silver ions to diffuse into the spongy structure and distribute evenly through the material as well as along the cellulose nanofiber surfaces. The silver nanoparticles, either as individual particles or aggregates inside the cellulose matrix, are clearly visible (Figure $3 \mathrm{~b}-\mathrm{d}$ ). To observe the distribution of the $\mathrm{Ag}$ nanoparticles more precisely, the sample images were recorded in the back scattering mode (Figure 3c), wherein the bright spots refer to Ag nanoparticles due to the strong back scattering of the electrons because it has a higher atomic number compared to that of the other constituents $(\mathrm{O}, \mathrm{H})$. It is observed that most of the particles are attached to the fiber surfaces, whereas some of them are trapped inside the matrix as agglomerates. The EDS elemental mapping (Figure S2) showed
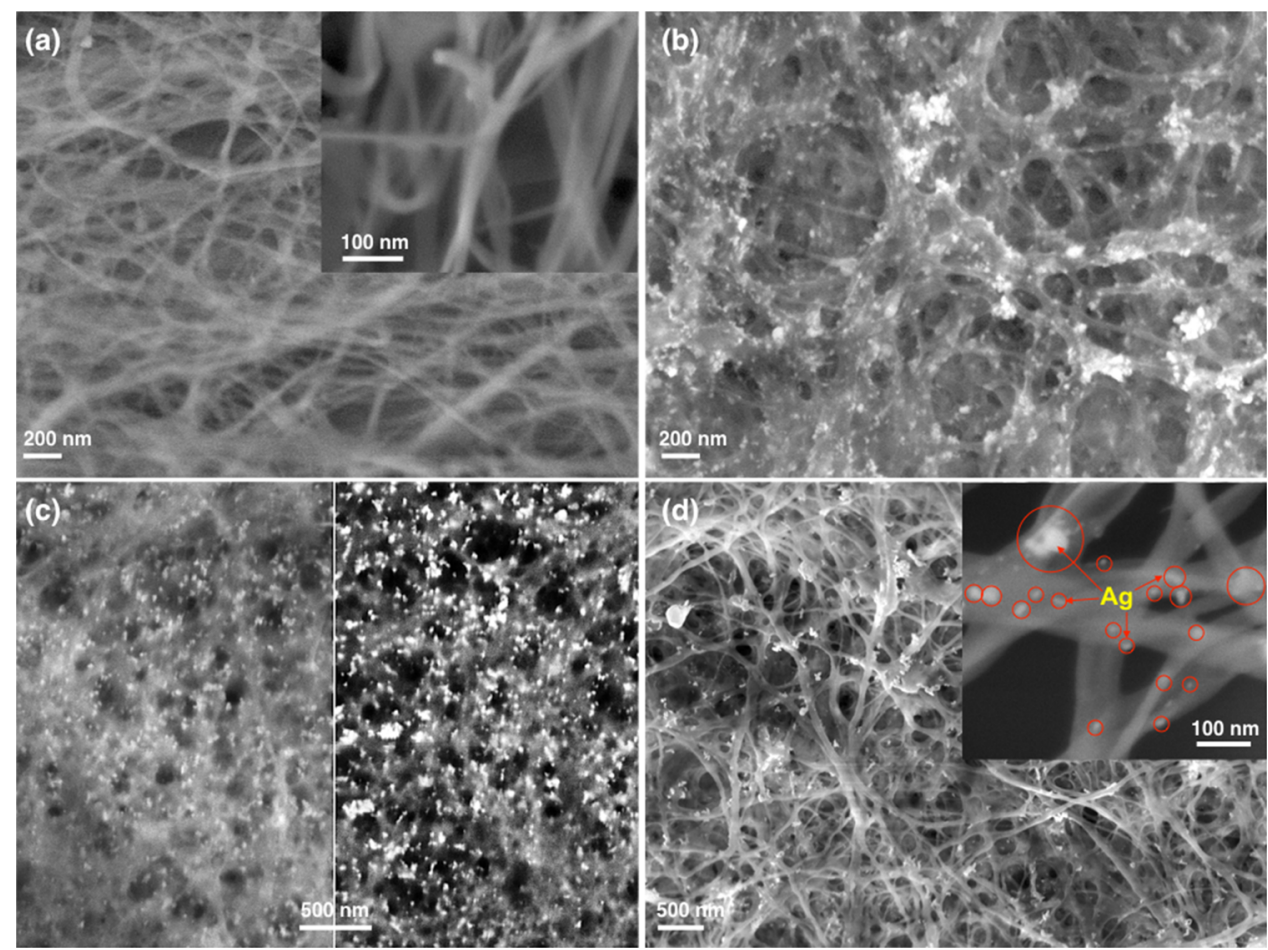

Figure 3. Scanning electron microscopic morphology of (a) pure BC, (b) Ag/BC focused at the surface, (c) SEM image along with back scattering measured on the same spot, and (d) cross-sectional analyses. The insets of (a) and (d) show higher magnification of the respective images. 
quite a homogeneous distribution of silver along the fibers on the $\mathrm{BC}$ surface. The scenario is more clear with the crosssectional analysis shown in Figure 3d, wherein individual particles, about 5-12 $\mathrm{nm}$ in diameter, are clearly visible (marked with red circles), which are attached on the surface of the cellulose nanofiber.

The dynamics of the bacterial growth in the culture medium was investigated by placing three $\mathrm{Ag} / \mathrm{BC}$ pellicles with three different concentrations in a fixed amount of bacteria solution. The growth was observed by measuring the optical density of the solution at $600 \mathrm{~nm}$ by optical spectrometry. The average value of the three consecutive measurements from three independent samples of each concentration was used to draw the graph. The data obtained from all samples are presented in Figure $4 \mathrm{a}$ as a histogram. It can be observed that $\mathrm{Ag} / \mathrm{BC}$ loaded
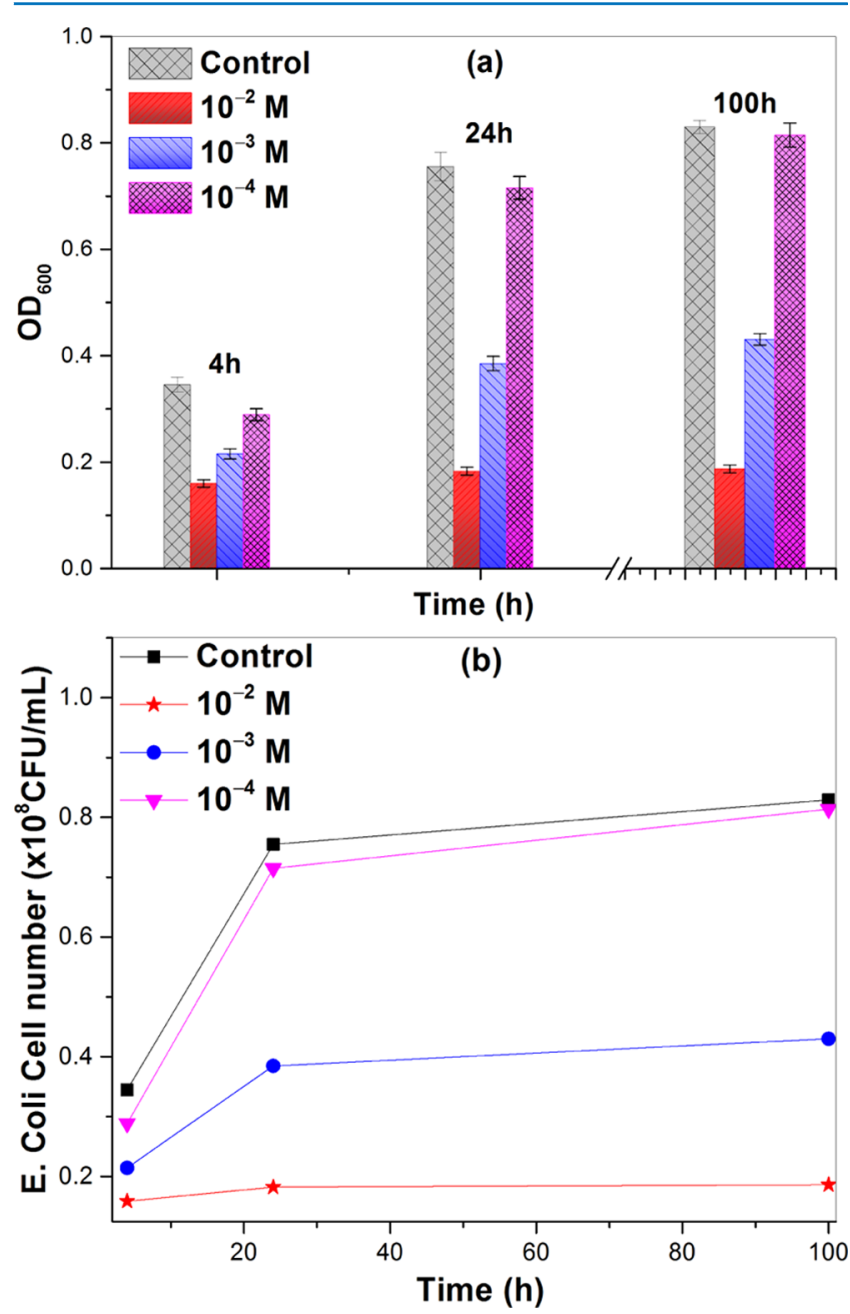

Figure 4. (a) Histogram and (b) growth dynamics of Escherichia coli with incubation time, using three different concentrations of $\mathrm{Ag} / \mathrm{BC}$ composite membranes. $\mathrm{OD}_{600}$ represents the optical density of the respective culture media. The error bar represents the standard deviation $(\mathrm{n}=3)$.

with a higher amount of silver shows strong antibacterial activity, wherein the OD value remains almost similar even after $100 \mathrm{~h}$ of incubation, whereas the bacterial growth is medium with a $10^{-3} \mathrm{M} \mathrm{Ag} / \mathrm{BC}$ sample showing moderate activity and the growth rate is a little lower than that of the pure $\mathrm{BC}$ sample in the case of $10^{-4} \mathrm{MAg} / \mathrm{BC}$, exhibiting the lowest antibacterial activity. The dynamic growth curve is presented in Figure $4 \mathrm{~b}$.
From this analysis, the minimal Ag concentration that could be loaded to the $\mathrm{BC}$ matrix can be determined, and further experimentation was performed with the $10^{-2} \mathrm{M} \mathrm{Ag} / \mathrm{BC}$ sample. Further increasing of the $\mathrm{Ag}$ concentration did not enhance the activity significantly, and at the same time it would blacken the composite pellicles and might increase the silver release rate from the sample that could limit its practical application toward wound healing.

The disc diffusion method was adopted to further prove the antibacterial performance of $\mathrm{Ag} / \mathrm{BC}$ composites, as the inhibition zone can be directly measured, which is one of the popular methods to establish the antibacterial activity. The photographs of $\mathrm{Ag} / \mathrm{BC}$ pellicles with different $\mathrm{Ag}$ concentrations are presented in Figure 5. The trend of the inhibition zone formation is analogous to the dynamic growth curve, as we discussed before, in which the $10^{-2} \mathrm{M} \mathrm{Ag} / \mathrm{BC}$ sample shows the highest level of activity. The increasing silver concentration is also in accordance with the color change of the respective composite samples. To measure the inhibition zone, the best performing pellicle was cut into a circular disk of about $10 \mathrm{~mm}$ in diameter along with pure $\mathrm{BC}$ serving as the reference (Figure $5 \mathrm{~d}, \mathrm{e})$. The distance from the outer surface of $\mathrm{Ag} / \mathrm{BC}$ to the bacterial colony-forming zone could be measured to about 6.5 $\mathrm{mm}$, which is good enough as an antimicrobial substrate.

The releasing behavior of silver from the antibacterial substrate is an important issue because an excessive amount of silver release, either as particles or in ionic form, could damage the human cells, limiting its applicability. On the other hand, if silver is too strongly embedded and not released, a poor antimicrobial activity will result. Figure 6 shows the amount of silver released from the $\mathrm{Ag} / \mathrm{BC}$ matrix as a function of immersion time. It is interesting to notice that the maximum release happened after $24 \mathrm{~h}$ of immersion, after which the concentration remained quite fixed even after 7 days of immersion, as seen from the curve. The counted value of $\mathrm{Ag}$ in $\mathrm{mg} / \mathrm{L}$ is reported in a tabular form inside the figure. This low release rate of silver from the $\mathrm{BC}$ pellicles could be explained due to the strong attachment of the $\mathrm{Ag}$ particles to the $\mathrm{BC}$ fiber surfaces as well as due to the agglomeration of the particles that are trapped within the nanofibrillated network. The above result also confirms the nontoxicity of the $\mathrm{Ag} / \mathrm{BC}$ samples to human cells, ${ }^{40}$ ensuring their potential use in wound treatment against bacterial and fungal growth.

As a summary, it can be said that the silver-functionalized BC composite prepared with a silver solution of $10^{-2} \mathrm{M}$ (7-9 wt \% of $\mathrm{Ag}$ with respect to cellulose) could be considered as the limiting silver concentration in our case for achieving the best antibacterial activity, without allowing the possibility of leaching the silver into the treating media, thus offering the lowest possible risk of contamination toward toxicity. A higher amount of silver loading resulted in the blackening of the membranes and increased silver leaching due to the silver nanoparticles being loosely bound to the $\mathrm{BC}$ fibers even after washing with deionized water several times. Different workers have postulated various amounts of silver loading in the cellulosic materials ranging from 0.8 to $35.82 \mathrm{wt} \%$, depending on the deposition/impregnation method and the type of the substrates being used. ${ }^{5,6,27,28,42,43}$ In our case, the strong binding of the $\mathrm{Ag}^{+}$ions to the $\mathrm{BC}$ nanofibers in the impregnation stage could result into this amount of silver loading that is comparable to that in the previous works. ${ }^{6,42,43}$ The antibacterial activity of the $\mathrm{Ag} / \mathrm{BC}$ composites was directly determined by the formation of the zone of inhibition that directly reflects the action of the 


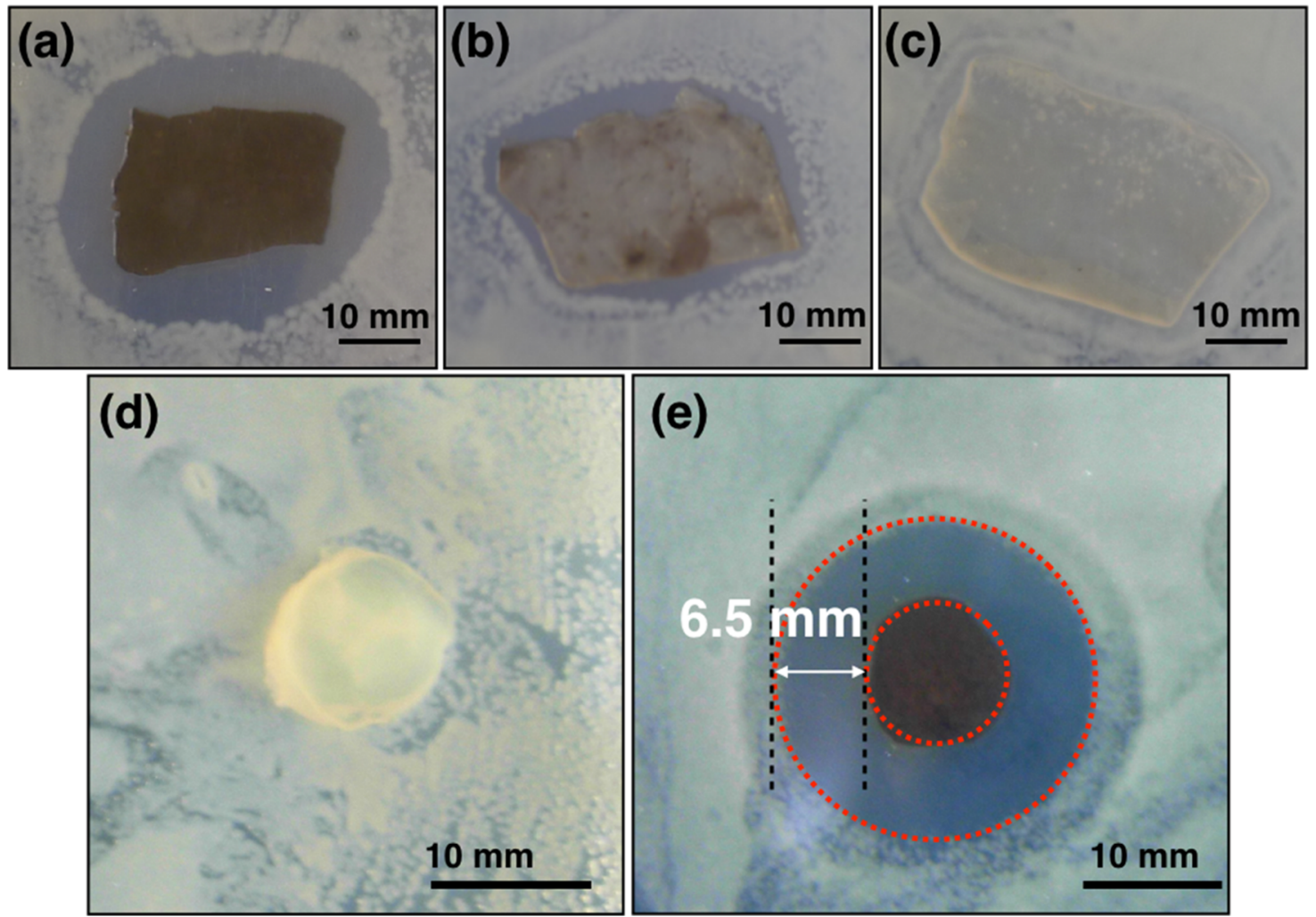

Figure 5. Photographs of antibacterial performance of $\mathrm{Ag} / \mathrm{BC}$ pellicles with three chosen samples at different $\mathrm{Ag}$ concentrations, (a) $10^{-2} \mathrm{M},(\mathrm{b})$ $10^{-3} \mathrm{M}$, and (c) $10^{-4} \mathrm{M}$. (d, e) Photographs taken with disk-shaped $\mathrm{BC}$ and $\mathrm{Ag} / \mathrm{BC}$ at $10^{-2} \mathrm{M} \mathrm{AgNO}_{3}$ concentration to calculate the inhibition zone.

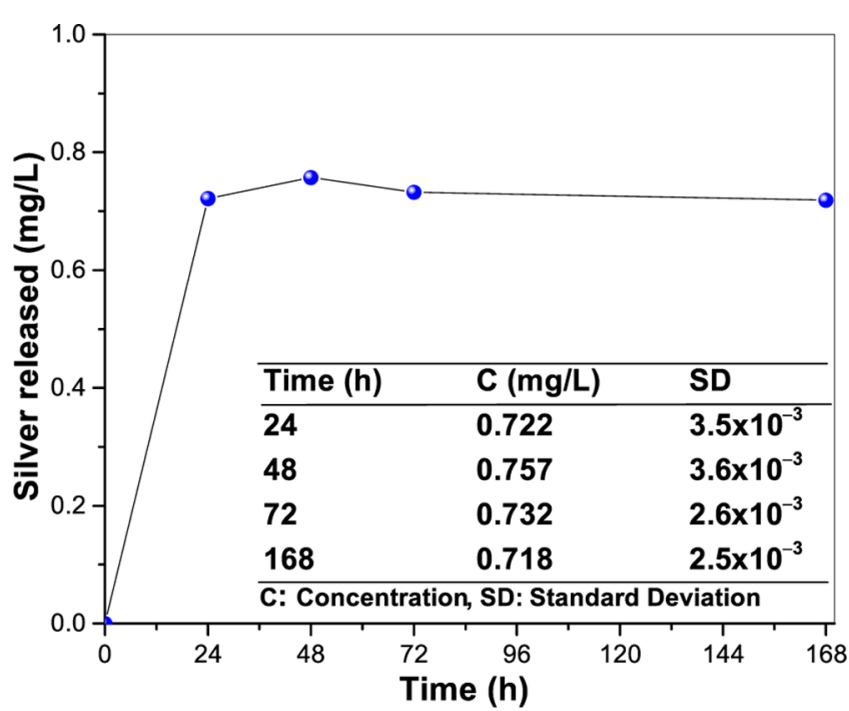

Figure 6. Silver-releasing behavior as a function of the immersion time. The equivalent concentration of $\mathrm{Ag}$ in $\mathrm{mg} / \mathrm{L}$ is calculated from the parts per billion ( $\mathrm{ppb})$ value obtained directly from the inductively coupled plasma (ICP) analysis.

antimicrobial agents. The inhibition zone observed with the best performing sample well justifies the high bacteria-killing activity of the $\mathrm{Ag} / \mathrm{BC}$ composite, as observed by the other researchers. ${ }^{27,28,42,44}$ As we already discussed, pure BC is useful as a natural wound dressing material because it can provide a highly moist environment due to higher water-retention capability that prevents dehydration of tissues and cell death, resulting in faster skin repair. But pure BC does not show antibacterial activity to prevent infections in the affected area.
In our case as well, pure BC (control sample) did not show any antibacterial activity where continuous bacterial growth (Figure $4 a, b)$ and no zone of inhibition were observed (Figure 5), whereas $\mathrm{Ag} / \mathrm{BC}$ composites, even with very low amount of $\mathrm{Ag}$, showed good antimicrobial property. The mechanism of antibacterial activity of silver nanoparticles is not fully understood and there are ongoing debates in this issue. ${ }^{46}$ However, in our case of $\mathrm{Ag} / \mathrm{BC}$ composites, it could be said that in the moist environment, contributed from both, the $\mathrm{BC}$ membrane and the wound exudate, silver ions $\left(\mathrm{Ag}^{+}\right)$are released from the silver nanoparticles that subsequently penetrate into the bacterial cells and interact by damaging the cell membrane. ${ }^{3045,46}$ The silver-ion release is favored in our case thanks to the porous channel of the fibrous BC membranes. This is confirmed from the silver release data (Figure 6), wherein fast release of silver is observed in the first $24 \mathrm{~h}$ time period. Now, compared with the silver functionalization of BC, most of the previous works show either chemical reduction of silver by using inorganic or organic reducing agents and/or the hydrothermal reduction method, which are both time consuming and need rigorous washing steps to remove the contaminants. As in our case, no other reducing agents were used, there is no risk of chemical contamination, and the $\mathrm{Ag} / \mathrm{BC}$ composites could be safely used as woundhealing membranes to fight against microorganisms.

\section{CONCLUSIONS}

Silver nanoparticles sized from 5 to $12 \mathrm{~nm}$, with narrow size distribution, were successfully deposited on the BC matrix. The highly porous cellulose pellicle, as a substrate, favored the diffusion of the silver ion and the hydroxyl group-rich cellulose fiber surface accelerated the deposition of ionic silver, which 
turned into metallic silver when exposed to UV radiation. Silver nanoparticles are supposed to firmly attach to the nanofibers because silver release was observed to be very slow. The attachment of silver to the cellulose fibers was confirmed by morphological analyses, although some aggregated nanoparticles co-existed inside the void matrix. The minimum amount of silver loading into the cellulose matrix with maximum antimicrobial activity was evaluated by performing a series of bacterial killing tests. $\mathrm{Ag} / \mathrm{BC}$, with optimal silver loading, showed the highest antibacterial activity, with a strong killing rate even for a longer time period. The fixed concentration of silver release after a certain period confirmed the stability of the $\mathrm{Ag}$ nanoparticles inside the composite matrix, reducing the risk of toxicity when applied to wound healing. As the composites are very stable in a moist environment, which also may help the wound-healing process, once prepared, they could be stored for a longer time period and could be beneficial in general wound healing and surgical cases.

\section{EXPERIMENTAL SECTION}

Materials. Black tea bags (Sir Bolton Company), sucrose (commercial product), vinegar (commercial product), and Kombucha tea were purchased from the local shops. Silver nitrate $\left(\mathrm{AgNO}_{3}\right)$, sodium hydroxide $(\mathrm{NaOH})$, and absolute ethanol (99.8\%) were purchased from Sigma-Aldrich and used without further modification. Agar powder was purchased from A.C.E.F., Luria-Bertani (LB) broth (Miller), and E. coli were purchased from VWR.

Preparation of Pure BC. BC pellicles were obtained from Kombucha strains by the fermentation process of the sweetened black tea with Acetobacter strains. The tea fungus that is composed of an upper cellulosic pellicle and a lower liquid broth was activated every 2 weeks according to the procedure described by Chen and Liu, with some modifications. ${ }^{41}$ The culture medium was prepared by adding sucrose and tea bags to boiling water $(1 \mathrm{~L})$. After removing the tea bags, the $\mathrm{pH}$ value of the broth was adjusted to $\sim 3.0$ by adding acetic acid. Finally, the cellulosic pellicle pieces and liquid broth of the tea fungus were added to the cooled tea broth. The fermentation process was carried out at room temperature $\left(28^{\circ} \mathrm{C}\right)$ for 15 days in a static culture condition. New pellicles of cellulose were grown on the surface of the broth. These pellicles and the tea fungus were used to inoculate new fermentations. The pellicles were washed with distilled water and boiled in $0.5 \mathrm{M} \mathrm{NaOH}$ solution. To extract the endotoxin from the BC samples, they were placed in a depyrogenated sample container and boiled with endotoxin free water four times. At this stage, BC could be used for further experimentation.

Preparation of $\mathrm{Ag} / \mathrm{BC}$ Nanocomposites. The purified $\mathrm{BC}$ pellicles were cut into small pieces and soaked in three molar concentrations of $\mathrm{AgNO}_{3}\left(10^{-2}, 10^{-3}\right.$, and $\left.10^{-4} \mathrm{M}\right)$ in a $100 \mathrm{~mL}$ glass beaker and left overnight in a dark condition to make the $\mathrm{Ag}^{+}$ions react with the BC fibrils. An ethanol-water mixture $(50 / 50$ by weight ratio) was used as the solvent. After impregnation, the $\mathrm{BC}$ pellicles were irradiated with UV light (maximum radiation at $365 \mathrm{~nm}, 500 \mathrm{~W}$, Jelosil Srl) for $15 \mathrm{~min}$. Then, the treated samples were washed thoroughly with ethanol and distilled water, followed by autoclaving at $121{ }^{\circ} \mathrm{C}$ for $10 \mathrm{~min}$ and finally stored in deionized water at $4{ }^{\circ} \mathrm{C}$. For morphological characterizations, the $\mathrm{BC}$ and $\mathrm{Ag} / \mathrm{BC}$ pellicles were freeze-dried to retain the $3 \mathrm{D}$ weblike structure.
Characterizations. The XRD pattern of the dried $\mathrm{BC}$ and $\mathrm{Ag} / \mathrm{BC}$ composites was recorded on a Panalytical X'Pert Pro Xray diffractometer, using $\mathrm{Ni}$-filtered $\mathrm{Cu} \mathrm{K} \alpha$ radiation $(\lambda=$ $1.5406 \AA$ ), operating at $40 \mathrm{kV}$ and $30 \mathrm{~mA}$, with a step size of $0.02^{\circ}$ and $5 \mathrm{~s}$ dwell time. FTIR were accumulated in the attenuated total reflectance mode with a Perkin-Elmer Spectrum One spectrometer at a frequency range of 4000$400 \mathrm{~cm}^{-1}$, with the resolution of $4 \mathrm{~cm}^{-1}$ and 32 scans for each sample. TGA of the freeze-dried $\mathrm{BC}$ and $\mathrm{Ag} / \mathrm{BC}$ composites were carried out to with a Mettler thermoanalyzer (Mettler Toledo, Star system) at a heating rate of $10^{\circ} \mathrm{C} / \mathrm{min}$ in nitrogen atmosphere. Morphological characterizations of the samples were performed on a Zeiss (Sigma VP; Carl Zeiss, Germany) FESEM. To perform the analyses, a thin slice was cut from the freeze-dried cellulose with a sharp stainless steel blade and placed on the carbon tape of the sample holder. The EDS analyses were performed with an EVO 40XVP (Carl Zeiss, Germany) scanning electron microscope equipped with a Bruker-made XFlash detector (SDD 5010; Bruker Nano Germany).

Silver Release Investigation. Silver-releasing test from the $\mathrm{Ag} / \mathrm{BC}$ pellicles were conducted in the distilled water at room temperature $\left(\sim 28{ }^{\circ} \mathrm{C}\right)$. To perform this test, the pellicles were cut into $1 \times 1 \times 0.5 \mathrm{~cm}^{3}$ in size and kept in a closed polypropylene container by adding $100 \mathrm{~mL}$ of distilled water. Five $\mathrm{ml}$ aliquots were taken out from the container at time intervals of 24, 48, 72, and $168 \mathrm{~h}$, and equivalent amounts of water were replaced in the container periodically to maintain the total volume of the solution. The presence of silver in the water solution and its quantitative analyses were performed by ICP emission spectrometry (ES) on a Perkin-Elmer ICP-ES instrument. Prior to the analysis, the ICP instrument was calibrated with the standard silver nitrate solution of three known concentrations. The sample aliquots were digested with a 1 wt $\% \mathrm{HCl} / \mathrm{HNO}_{3}$ mixture ( $1 / 1$ by weight), and the acid mixture was used as the blank sample. For each time period, three successive measurements were performed from three different samples.

Antibacterial Activity Evaluation. The antibacterial activity of $\mathrm{Ag} / \mathrm{BC}$ pellicles was evaluated by the disk diffusion and growth curve methods against E. coli as the model Gramnegative bacteria. The disk diffusion method was performed on an LB nutrient medium solid agar petri dish. The silver nanoparticle-impregnated BC was cut into a disk shape of 10 $\mathrm{mm}$ diameter and sterilized with a low power UV lamp for 5 min, for each side. Then, the disks were placed on the agar plate inoculated with $4.8 \times 10^{7} \mathrm{cfu} / \mathrm{mL}$ of $E$. coli. and incubated overnight at $37^{\circ} \mathrm{C}$. Silver-free BC pellicles were also incubated under the same conditions as control. The antibacterial activities of the samples were monitored by observing the inhibition zone formed surrounding the pellicles. The inhibition zone length was counted by averaging three independent experiments. In the growth curve method, a culture of $E$. coli was placed in the $\mathrm{LB}$ medium at $37^{\circ} \mathrm{C}$ until the optical density $(\mathrm{OD})$ at $600 \mathrm{~nm}$ reached $0.6\left(\mathrm{OD}_{600}\right)$. Ten microliters of E. coli $\left(4.8 \times 10^{7} \mathrm{cfu} / \mathrm{mL}\right)$ suspension was transferred in a test tube with an LB liquid medium, and a test sample was kept inside the tube. The culture was held at $37{ }^{\circ} \mathrm{C}$ for $16 \mathrm{~h}$. The growth of the cells was determined by observing the turbidity of the cell culture. The bacterial culture was withdrawn from the tube and the $\mathrm{OD}$ value at $600 \mathrm{~nm}$ was measured by a spectrophotometer. The experiments were performed in triplicate. 


\section{ASSOCIATED CONTENT}

\section{S Supporting Information}

The Supporting Information is available free of charge on the ACS Publications website at DOI: 10.1021/acsomega.7b00442.

TGA of BC and Ag/BC nanocomposites with different Ag loading (Figure S1), estimation of silver loading from TGA and EDS analyses (Table S1), EDS elemental mapping on the $\mathrm{Ag} / \mathrm{BC}$ sample (Figure S2), and digital images of antibacterial activity of $\mathrm{Ag} / \mathrm{BC}$ membranes (Figure S3) (PDF)

\section{AUTHOR INFORMATION}

\section{Corresponding Author}

*E-mail: sudipto.pal@unisalento.it.

\section{ORCID}

Sudipto Pal: 0000-0002-9812-7039

Notes

The authors declare no competing financial interest.

\section{ACKNOWLEDGMENTS}

The authors thank Dr. Fabio Marzo (University of Salento) for providing the FESEM facility. Dr. Leander Tapfer (ENEA, Brindisi Research Centre, Italy) is thankfully acknowledged for providing XRD analyses.

\section{REFERENCES}

(1) Iguchi, M.; Yamanaka, S.; Budhiono, A. Bacterial Cellulose-A Masterpiece of Nature's Arts. J. Mater. Sci. 2000, 35, 261-270.

(2) Zhu, C.; Li, F.; Zhou, X.; Lin, L.; Zhang, T. KombuchaSynthesized Bacterial Cellulose: Preparation, Characterization, and Biocompatibility Evaluation. J. Biomed. Mater. Res., Part A 2014, 102, $1548-1557$.

(3) Huang, Y.; Zhu, C.; Yang, J.; Nie, Y.; Chen, C.; Sun, D. Recent Advances in Bacterial Cellulose. Cellulose 2014, 21, 1-30.

(4) Wu, Z. Y.; Liang, H. W.; Chen, L. F.; Hu, B. C.; Yu, S. H. Bacterial Cellulose: A Robust Platform for Design of Three Dimensional Carbon-Based Functional Nanomaterials. Acc. Chem. Res. 2016, 49, 96-105.

(5) Sureshkumar, M.; Siswanto, D. Y.; Lee, C. K. Magnetic Antimicrobial Nanocomposite Based on Bacterial Cellulose and Silver Nanoparticles. J. Mater. Chem. 2010, 20, 6948-6955.

(6) Kucińska-Lipka, J.; Gubanska, I.; Janik, H. Bacterial Cellulose in the Field of Wound Healing and Regenerative Medicine of Skin: Recent Trends and Future Prospectives. Polym. Bull. 2015, 72, 23992419.

(7) Shi, Z.; Zhang, Y.; Phillips, G. O.; Yang, G. Utilization of Bacterial Cellulose in Food. Food Hydrocolloids 2014, 35, 539-545.

(8) Santos, S. M.; Carbajo, J. M.; Quintana, E.; Ibarra, D.; Gomez, N.; Ladero, M.; Eugenio, M. E.; Villar, J. C. Characterization of Purified Bacterial Cellulose Focused on its Use on Paper Restoration. Carbohydr. Polym. 2015, 116, 173-181.

(9) Keshk, S. M. Bacterial Cellulose Production and its Industrial Applications. J. Bioprocess. Biotech. 2014, 04, 150.

(10) Svensson, A.; Nicklasson, E.; Harrah, T.; Panilaitis, B.; Kaplan, D. L.; Brittberg, M.; Gatenholm, P. Bacterial Cellulose as a Potential Scaffold for Tissue Engineering of Cartilage. Biomaterials 2005, 26, 419-431.

(11) Zang, S.; Zhang, R.; Chen, H.; Lu, Y.; Zhou, J.; Chang, X.; Qiu, G.; Wu, Z.; Yang, G. Investigation on Artificial Blood Vessels Prepared from Bacterial Cellulose. Mater. Sci. Eng., Proc. Conf. 2015, 46, 111117.

(12) Lee, H. Y.; Park, H. K.; Lee, Y. M.; Kim, K.; Park, S. B. A practical Procedure for Producing Silver Nanocoated Fabric and its Antibacterial Evaluation for Biomedical Applications. Chem. Commun. 2007, 2959-2961.
(13) Fei, X.; Jia, M.; Du, X.; Yang, Y.; Zhang, R.; Shao, Z.; Zhao, X.; Chen, X. Green Synthesis of Silk Fibroin-Silver Nanoparticle Composites with Effective Antibacterial and Biofilm-Disrupting Properties. Biomacromolecules 2013, 14, 4483-4488.

(14) Wang, X.; Wu, H. F.; Kuang, Q.; Huang, R. B.; Xie, X. X.; Zheng, L. S. Shape-Dependent Antibacterial Activities of $\mathrm{Ag}_{2} \mathrm{O}$ Polyhedral Particles. Langmuir 2010, 26, 2774-2778.

(15) Rieger, K. A.; Cho, H. J.; Yeung, H. F.; Fan, W.; Schiffman, J. D. Antimicrobial Activity of Silver Ions Released from Zeolites Immobilized on Cellulose Nanofiber Mats. ACS Appl. Mater. Interfaces 2016, 8, 3032-3040.

(16) Lansdown, A. B. G. A Pharmacological and Toxicological Profile of Silver as an Antimicrobial Agent in Medical Devices, Advances in Pharmacological Sciences. Adv. Pharmacol. Sci. 2010, 2010, 1-16.

(17) You, C.; Han, C.; Wang, X.; Zheng, Y.; Li, Q.; Hu, X.; Sun, H. The Progress of Silver Nanoparticles in the Antibacterial Mechanism, Clinical Application and Cytotoxicity. Mol. Biol. Rep. 2012, 39, 91939201.

(18) Ge, L.; Li, Q.; Wang, M.; Ouyang, J.; Li, X.; Xing, M. M. Nanosilver Particles in Medical Applications: Synthesis, Performance, and Toxicity. Int. J. Nanomed. 2014, 9, 2399-2407.

(19) Paladini, F.; Pollini, M.; Sannino, A.; Ambrosio, L. Metal-Based Antibacterial Substrates for Biomedical Applications. Biomacromolecules 2015, 16, 1873-1885.

(20) Bao, H.; Yu, X.; Xu, C.; Li, X.; Li, Z.; Wei, D.; Liu, Y. New Toxicity Mechanism of Silver Nanoparticles: Promoting Apoptosis and Inhibiting Proliferation. PLoS One 2015, 10, No. e0122535.

(21) Katsumiti, A.; Gilliland, D.; Arostegui, I.; Cajaraville, M. P. Mechanisms of Toxicity of Ag Nanoparticles in Comparison to Bulk and Ionic Ag on Mussel Hemocytes and Gill Cells. PLoS One 2015, 10, No. e0129039.

(22) Sotiriou, G. A.; Pratsinis, S. E. Antibacterial Activity of Nanosilver Ions and Particles. Environ. Sci. Technol. 2010, 44, 56495654.

(23) Fabrega, J.; Fawcett, S. R; Renshaw, J. C.; Lead, J. R. Silver nanoparticle impact on bacterial growth: Effect of $\mathrm{pH}$, con- centration, and organic matter. Environ. Sci. Technol. 2009, 43, 7285-7290.

(24) Wijnhoven, S. W. P.; Peijnenburg, W. J. G. M.; Herberts, C. A.; Hagens, W. I.; Oomen, A. G.; Heugens, E. H. W.; Roszek, B.; Bisschops, J.; Gosens, I.; Meent, D. K. D.; Dekkers, S.; Jong, W. H. D.; Zijverden, M. V.; Sips, A. J. A. M.; Geertsma, R. E. Nano-Silver-A Review of Available Data and Knowledge Gaps in Human and Environmental Risk Assessment. Nanotoxicology 2009, 3, 109-138.

(25) Dos Santos, C. A.; Seckler, M. M.; Ingle, A. P.; Gupta, I.; Galdiero, S.; Galdiero, M.; Gade, A.; Rai, M. Silver Nanoparticles: Therapeutical Uses, Toxicity, and Safety Issues. J. Pharm. Sci. 2014, 103, 1931-1944.

(26) Xu, Z.; Li, M.; Li, X.; Liu, X.; Ma, F.; Wu, S.; Yeung, K. W. K.; Han, Y.; Chu, P. K. Antibacterial Activity of Silver Doped Titanate Nanowires on Ti Implants. ACS Appl. Mater. Interfaces 2016, 8, 16584-16594.

(27) Maneerung, T.; Tokura, S.; Rujiravanit, R. Impregnation of Silver Nanoparticles into Bacterial Cellulose for Antimicrobial Wound Dressing. Carbohydr. Polym. 2008, 72, 43-51.

(28) Yang, G.; Xie, J.; Hong, F.; Cao, Z.; Yang, X. Antimicrobial Activity of Silver Nanoparticle Impregnated Bacterial Cellulose Membrane: Effect of Fermentation Carbon Sources of Bacterial Cellulose. Carbohydr. Polym. 2012, 87, 839-845.

(29) Ifuku, S.; Tsuji, M.; Morimoto, M.; Saimoto, H.; Yano, H. Synthesis of Silver Nanoparticles Templated by TEMPO-Mediated Oxidized Bacterial Cellulose Nanofibers. Biomacromolecules 2009, 10, 2714-2717.

(30) Li, Z.; Wang, L.; Chen, S.; Feng, C.; Chen, S.; Yin, N.; Yang, J.; Wang, H.; Xu, Y. Facilely Green Synthesis of Silver Nanoparticles into Bacterial Cellulose. Cellulose 2015, 22, 373-383.

(31) Pinto, R. J. B.; Marques, P. A. A. P.; Neto, C. P.; Trindade, T.; Daina, S.; Sadocco, P. Antibacterial Activity of Nanocomposites of Silver and Bacterial or Vegetable Cellulosic Fibers. Acta Biomater. 2009, 5, 2279-2289. 
(32) Basuny, M.; Ali, I. O.; El-Gawad, A. A.; Bakr, M. F.; Salama, T. M. A Fast Green Synthesis of Ag Nanoparticles in Carboxymethyl Cellulose (CMC) through UV Irradiation Technique for Antibacterial Applications. J. Sol-Gel Sci. Technol. 2015, 75, 530-540.

(33) Lee, K. Y.; Quero, F.; Blaker, J. J.; Hill, C. A. S.; Eichhorn, S. J.; Bismarck, A. Surface Only Modification of Bacterial Cellulose Nanofibres with Organic Acids. Cellulose 2011, 18, 595-605.

(34) Cui, Q.; Zheng, Y.; Lin, Q.; Song, W.; Qiao, K.; Liu, S. Selective Oxidation of Bacterial Cellulose by $\mathrm{NO}_{2}-\mathrm{HNO}_{3}$. RSC Adv. 2014, 4, $1630-1639$.

(35) De, G.; Licciulli, A.; Massaro, C.; Tapfer, L.; Catalano, M.; Battaglin, G.; Meneghini, C.; Mazzoldi, P. Silver Nanocrystals in Silica by Sol-gel Processing. J. Non-Cryst. Solids 1996, 194, 225-234.

(36) Parikh, D. V.; Thibodeaux, D. P.; Condon, B. X-ray Crystallinity of Bleached and Cross-Linked Cottons. Text. Res. J. 2007, 77, 612616.

(37) Segal, L.; Creely, J. J.; Martin, A. E.; Conrad, C. M. An Empirical Method for Estimating the Degree of Crystallinity of Native Cellulose Using the X-ray Diffractometer. Tex. Res. J. 1959, 29, 786-794.

(38) Sarkar, D.; Ghosh, C. K.; Mukherjee, S.; Chattopadhyay, K. K. Three Dimensional $\mathrm{Ag}_{2} \mathrm{O} / \mathrm{TiO}_{2}$ Type-II $(\mathrm{p}-\mathrm{n})$ Nanoheterojunctions for Superior Photocatalytic Activity. ACS Appl. Mater. Interfaces 2013, $5,331-337$

(39) Paul, K. K.; Ghosh, R.; Giri, P. K. Mechanism of Strong Visible Light Photocatalysis by $\mathrm{Ag}_{2} \mathrm{O}-$ Nanoparticle-Decorated Monoclinic $\mathrm{TiO}_{2}$ (B) Porous Nanorods. Nanotechnology 2016, 27, No. 315703.

(40) Gliga, A. R.; Skoglund, S.; Wallinder, I. O.; Fadeel, B.; Karlsson, H. L. Size-Dependent Cytotoxicity of Silver Nanoparticles in Human Lung Cells: The Role of Cellular Uptake, Agglomeration and Ag Release. Part. Fibre Toxicol. 2014, 11, 11-17.

(41) Chen, C.; Liu, B. Y. Changes in Major Components of Tea Fungus Metabolites During Prolonged Fermentation”. J. Appl. Microbiol. 2000, 89, 834-839.

(42) Feng, J.; Shi, Q.; Li, W.; Shu, X.; Chen, A.; Xie, X.; Huang, X. Antimicrobial Activity of Silver Nanoparticles in Situ Growth on TEMPO-Mediated Oxidized Bacterial Cellulose. Cellulose 2014, 21, 4557-4567.

(43) Ye, D.; Zhong, Z.; Xu, H.; Chang, C.; Yang, Z.; Wang, Y.; Ye, Q.; Zhang, L. Construction of Cellulose/Nanosilver Sponge Materials and Their Antibacterial Activities for Infected Wounds Healing. Cellulose 2016, 23, 749-763.

(44) Chen, C.; Zhang, T.; Dai, B.; Zhang, H.; Chen, X.; Yang, J.; Liu, J.; Sun, D. Rapid Fabrication of Composite Hydrogel Microfibers for Weavable and Sustainable Antibacterial Applications. ACS Sustainable Chem. Eng. 2016, 4, 6534-6542.

(45) Hsueh, Y.-H.; Lin, K.-S.; Ke, W.-J.; Hsieh, C.-T.; Chiang, C.-L.; Tzou, D.-Y.; Liu, S.-T. The Antimicrobial Properties of Silver Nanoparticles in Bacillus Subtilis Are Mediated by Released Ag+ Ions. PLoS One 2015, 10, No. e0144306.

(46) Maiti, S.; Krishnan, D.; Barman, G.; Ghosh, S. K.; Laha, J. K. Antimicrobial Activities of Silver Nanoparticles Synthesized from Lycopersicon Esculentum Extract. J. Anal. Sci. Technol. 2014, 5, 40. 